\title{
Review of: "A simple immunoassay for extracellular vesicle liquid biopsy in microliters of non-processed plasma"
}

\author{
Stefano Fais ${ }^{1}$ \\ 1 Istituto Superiore di Sanità
}

Potential competing interests: The author(s) declared that no potential competing interests exist.

This study is not original. The author should make very clear which are the novelties respect to the paper below:

1. Logozzi M, De Milito A, Lugini L, Borghi M, Calabrò L, Spada M, Perdicchio M, Marino ML, Federici C, lessi E, Brambilla D, Venturi G, Lozupone F, Santinami M, Huber V, Maio M, Rivoltini L, Fais S. High levels of exosomes expressing CD63 and caveolin-1 in plasma of melanoma patients. PLoS One. 2009;4(4):e5219. MELANOMA PATIENTS

2. Logozzi M, Angelini DF, Giuliani A, Mizzoni D, Di Raimo R, Maggi M, Gentilucci A, Marzio V, Salciccia S, Borsellino G, Battistini L, Sciarra A, Fais S. Increased Plasmatic Levels of PSA-Expressing Exosomes Distinguish Prostate Cancer Patients from Benign Prostatic Hyperplasia: A Prospective Study. Cancers (Basel). 2019 Sep 27;11(10). pii: E1449. doi: 10.3390/cancers11101449. PROSTATE CANCER PATIENTS

3. Rodríguez Zorrilla S, Pérez-Sayans M, Fais S, Logozzi M, Gallas Torreira M, García García A. A Pilot Clinical Study on the Prognostic Relevance of Plasmatic Exosomes Levels in Oral Squamous Cell Carcinoma Patients. Cancers (Basel). 2019 Mar 26;11(3). pii: E429. doi: 10.3390/cancers11030429. ORAL CANCER PATIENTS

Moreover, a recent paper published in Methods in Enzymology summarized and commented the Immunocapture based technology(Logozzi M, Di Raimo R, Mizzoni D, Fais S.Immunocapture-based ELISA to characterize and quantify exosomes in both cell culture supernatants and body fluids. Methods Enzymol. 2020;645:155-180. doi: 10.1016/bs.mie.2020.06.011. Epub 2020 Jul 9); that was invented in my lab actually, and at the very beginning strongly criticized, as it occurs for the very novelties in science. I Would expect some real advance after up to 12 year from the first publication ; rather witnessing to something that looks like copy and paste. What is more disappointing is that nor the 2009 clinical trial in melanoma patients nor the most recent papers have been cited and commented; and this once again witnesses the bad faith of the authors Sorry for being so dry in my comment but what l've read is very much disappointing and for a 65 scientist 
like I'm this behaviour is a very bad story, NOT SO PROMISING FOR THE FUTURE. 